\title{
Application of Dynamic Voltage Restorer for Enhancing low voltage Ride-through capability of Doubly Fed Induction Generator
}

\author{
T.Samina, A.Bisharathu Beevi, S. RamaIyer
}

\begin{abstract}
Doubly Fed Induction Generator (DFIG) based wind Energy System are very sensitive to grid disturbance such as Symmetrical voltage sag. In this paper the authors propose a new method for application of Dynamic Voltage Restorer for enhancing the low voltage ride through capability of wind turbine driven Doubly Fed Induction Generator.
\end{abstract}

Keywords: Doubly Fed Induction Generator, Dynamic Voltage Restorer. Voltage sag, Rotor side controller, Grid side controller.

\section{INTRODUCTION}

The Doubly Fed Induction Generator (DFIG) is the most commonly used generator in wind power technology. A drop of one or more phase voltage can be especially damage the power electronic converter. For Symmetrical fault the drop is the same for three phases. The main drawback of the DFIG is that if a voltage sag occurs in the grid stator current will increase to a very high value . Due to magnetic coupling between stator and rotor ,according to law of conservation of flux this stator disturbance is further transferred to rotor. Due to this rotor current increases in a very high manner and a large fluctuation occurs for the dc link voltage. If a voltage sag occurs, the rotor of the Doubly Fed Induction Generator should be protected. Now a days the method used is bypassing the high rotor current through a resistor which is called crow bar, there by protecting the converters from the high current. The aim of this work is to analyze the nature of DFIG under grid voltage variations. In This paper Section I gives the introduction, The working of DFIG and Dynamic Voltage Restorer (DVR), is given in section II. Section III gives the behavior of DFIG during Symmetrical voltage sag. Section IV gives control using Dynamic Voltage Restorer and analysis and the conclusion is given in section $\mathrm{V}$.

\section{SYSTEM CONFIGURATION.}

The typical configuration of the DFIG -DVR wind turbine system is shown in Figure 1. Appendix-1 gives the parameters of DFIG used in this work. The Stator of the DFIG is directly connected to the grid, and rotor is connected through a bidirectional PWM converter.[1].

Revised Manuscript Received on September 15, 2020.

* Correspondence Author

T.Samina*, Associate Professor, College of Engineering, Thiruvanathapuram, India

A.Bisharthu Beevi, Lecturer, in Electrical Engineering, Govt .Engineering College, Kannur and served in various engineering colleges across Kerala.

S.RamaIyer, Professor, Electrical Department, and as Dean in College of Engineering, Thiruvananthapuram .

(C) The Authors. Published by Blue Eyes Intelligence Engineering and Sciences Publication (BEIESP). This is an open access article under the CC BY-NC-ND license (http://creativecommons.org/licenses/by-nc-nd/4.0/)
A Dynamic Voltage Restorer ,also known as series voltage booster mainly consists of three components.(a).Energy storage unit, here the energy from the input supply is rectified using shunt converter,(b)Inverter circuit, the voltage source inverter convert the dc voltage from the energy storage in to a three phase ac voltage which is controllable, and (c)Filter Circuit which avoid the ripple. The non lenier characteristics of the semi conductor device cause distortion in voltage wave forms . To overcome this high quality harmonic filtering is used. DFIG Control includes (a)Rotor side controller and(b) Grid side controller.

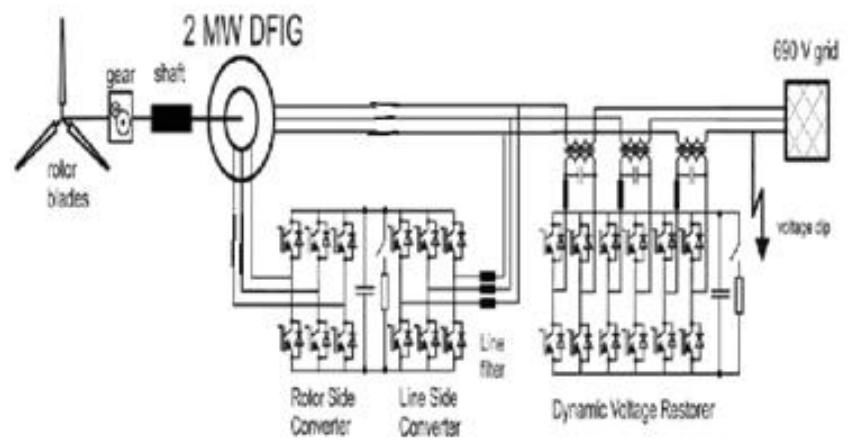

Fig. 1. DFIG-DVR System. .

(a) Rotor side controller

Field oriented control is used for controlling the power electronic converter on the rotor side. Reactive power of the stator proportional to rotor direct axis current and active power or torque is proportional to orthogonal axis component of rotor current. Figure 2 shows the block diagram of Rotor side controller.

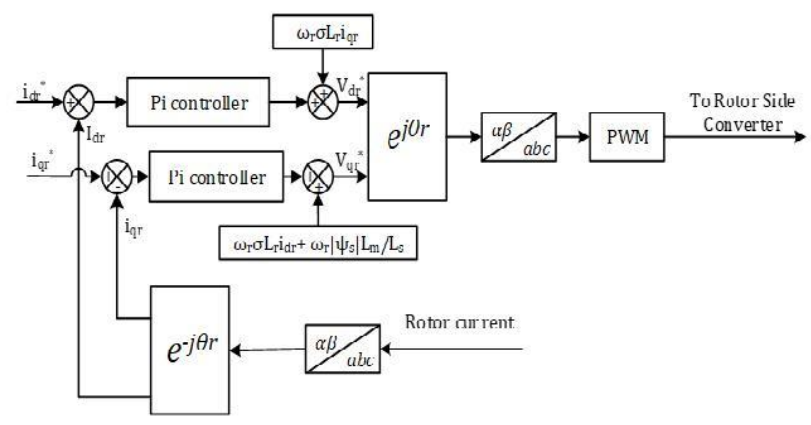

Fig. 2. Rotor side control of DFIG (b) Grid side controller

The dc link voltage has to be kept constant.

Published By:

Blue Eyes Intelligence Engineering and Sciences Publication 


\section{Application of Dynamic Voltage Restorer for Enhancing low voltage Ride-through capability of Doubly Fed Induction Generator}

The Grid side controller does this function. Here also grid side field-oriented control is used. The control of the dc link voltage is accomplished through the proper selection of required direct axis current and the perpendicular component of current controls the reactive power [2]. Figure 3 shows the block diagram of Grid side controller. For analysis purpose the equivalent circuit of DFIG is simplified as shown in Figure.4.[3]From the equivalent circuit shown vector diagram is obtained as shown in Figure.5

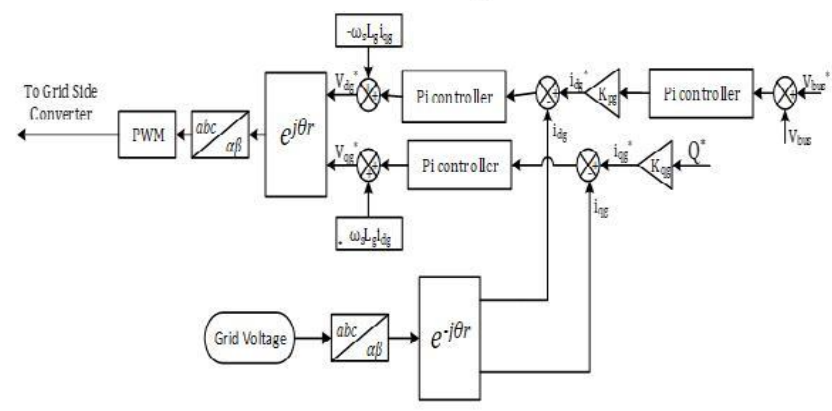

Fig. 3. Grid side control of DFIG

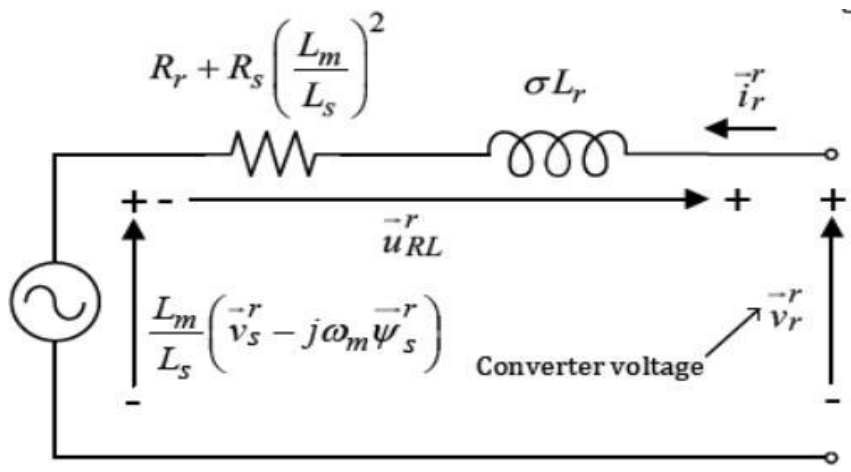

Fig. 4. DFIG Simplified Equivalent circuit.

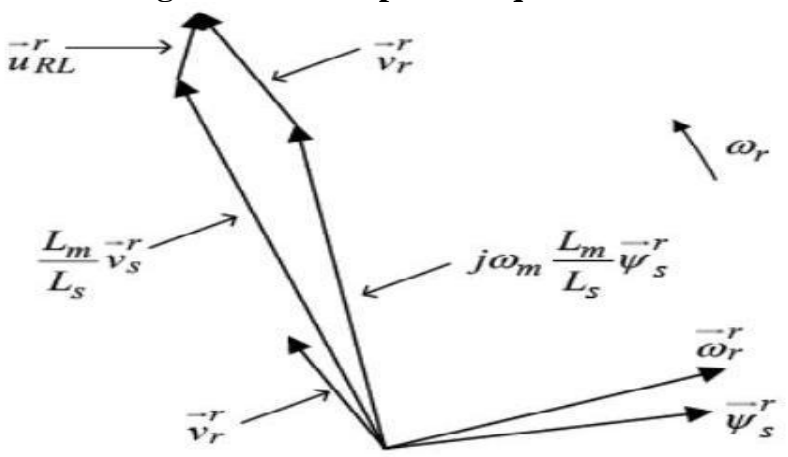

Fig. 5. DFIG

Voltage Vector diagram

III. DFIG WITH SYMMETRICAL VOLTAGE DIP

$\frac{d \varphi_{s}}{d t}=V_{s}-\frac{R_{s}}{L_{s}} \varphi_{s}+R_{s} \frac{L_{m}}{L_{s}} i_{r}$

$V_{r}=\frac{L_{m n}}{L_{s}}\left(V_{s}-j \omega_{m} \varphi_{s}\right)+\left[R_{r}+\left(\frac{L_{m m}}{L_{x}}\right)^{2} R_{s}\right] i_{r}+\sigma L_{r} \frac{d i_{r}}{d t}$

The equations 1 ans 2 shows the variation of stator flux and rotor voltage. The analysis is conducted by means of simulation using MATLAB, based on 2MW Wind turbine based DFIG Wind turbine system. Here the Voltage dip occures at a time period equals 3 seconds, as shown in Figure. 6 ,when the dip occures the grid voltage is only $10 \%$ of rated voltage. The crowbar is activated at the same time,connecting the additional resistance path in the machine.During the first instant of the dip,peak stator and rotor current and large torque occures as in Figure.8, Figure.7, and Figure.9. During sag period,entire high rotor current circulates through the crow bar,there by protecting the rotor side converter.

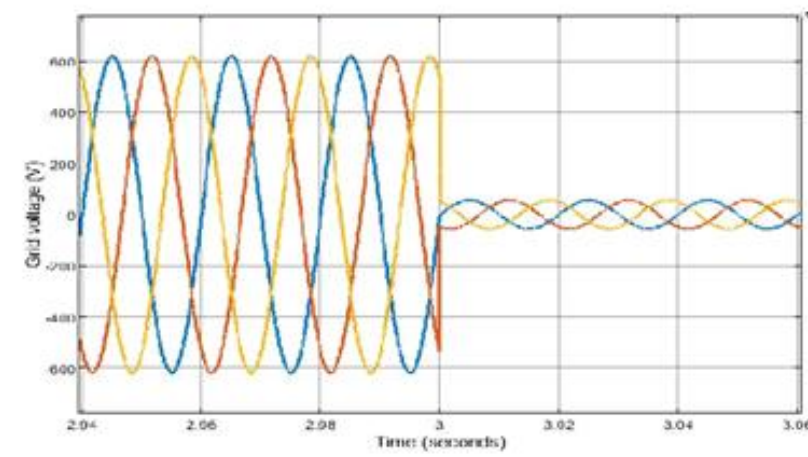

Fig. 6. Grid voltage with Symmetrical voltage sag

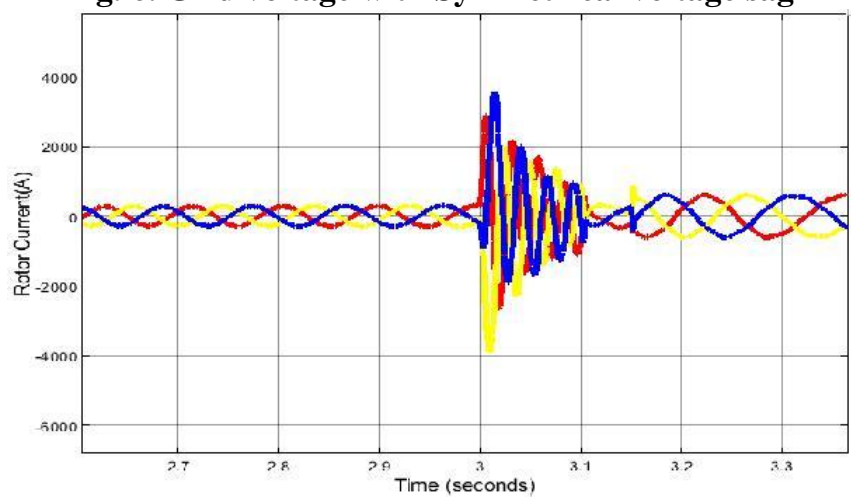

Fig. 7 DFIG Rotor current with Symmetrical voltage sag.

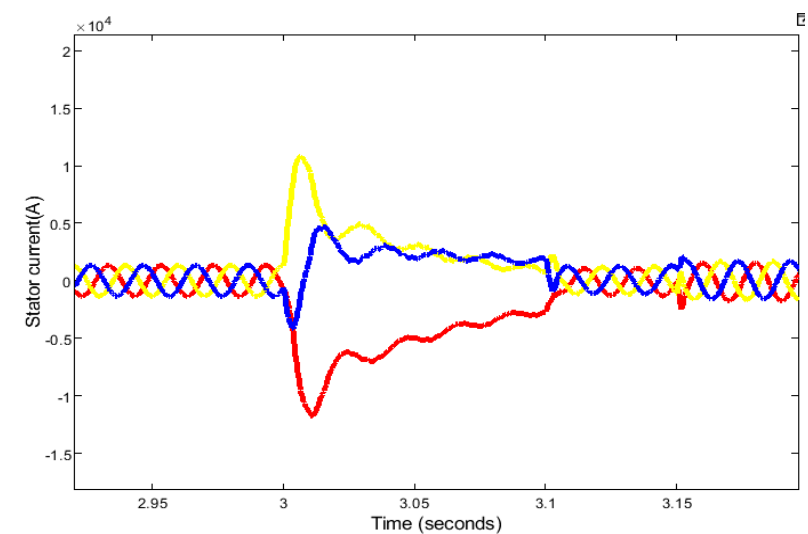

Fig. 8 DFIG Stator current with Symmetrical voltage sag

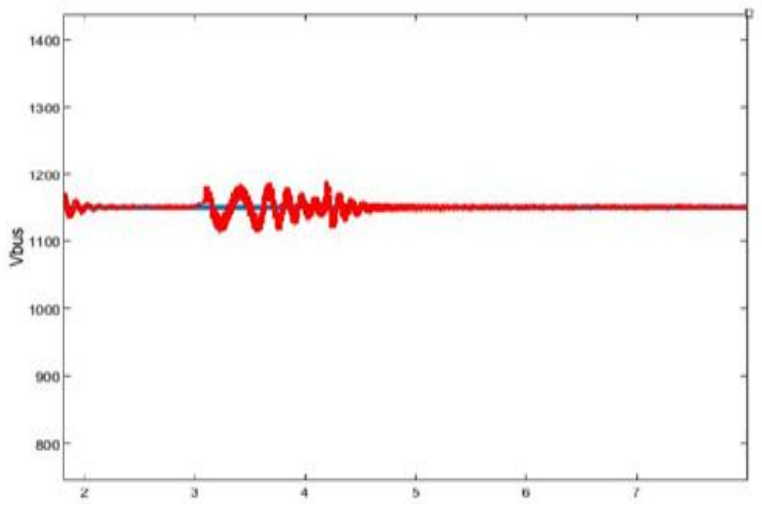

Fig.9 DC bus voltage with symmetrical voltage sag

Published By:

Blue Eyes Intelligence Engineering and Sciences Publication

(C) Cobvriaht: All riahts reserved.

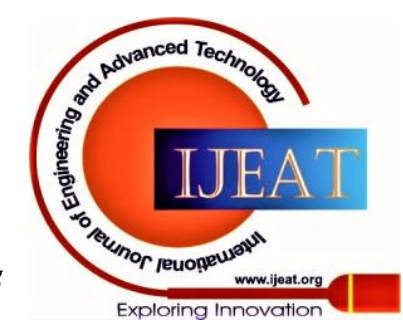




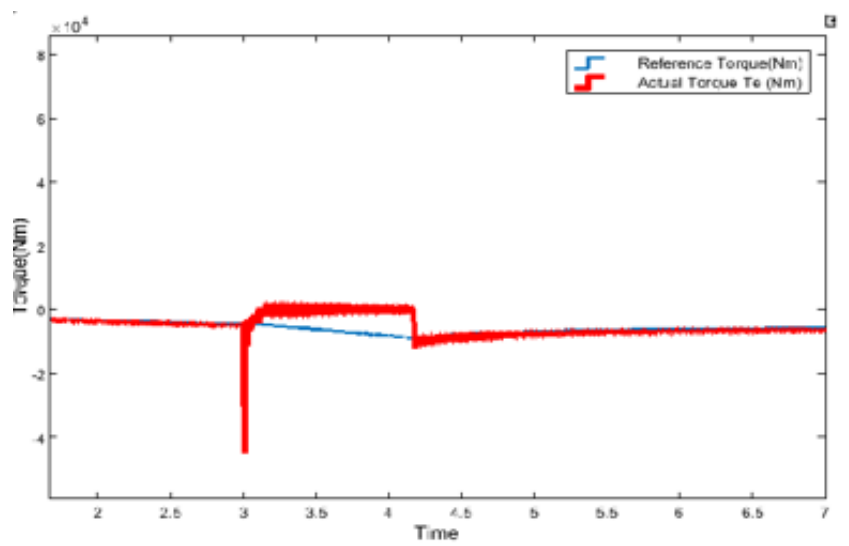

Fig. 10 DFIG Torque developed with symmetrical sag..

\section{DFIG WITH SYMMETRICAL VOLTAGE SAG AND DVR CONTRO}

As Explained in the preceding section even though a protective resistor is used the magnitude of stator and rotor current is very high during sag period. Also a large fluctuation is their in the dc link voltage.[4] In this work Dynamic Voltage Restorer is used for operating DFIG under voltage sag conditions. Here a three phase rectifier properly charges the capacitor. The losses in the single phase injection transformer is not considered in this work

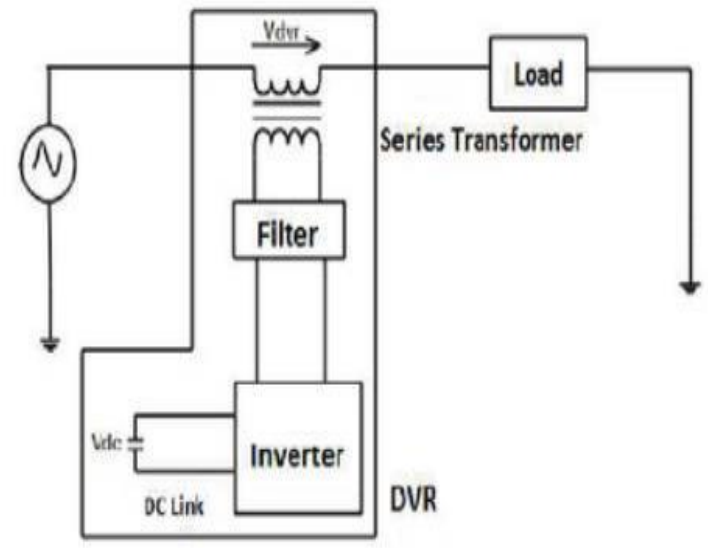

Fig.11 DVR Basic Circuit

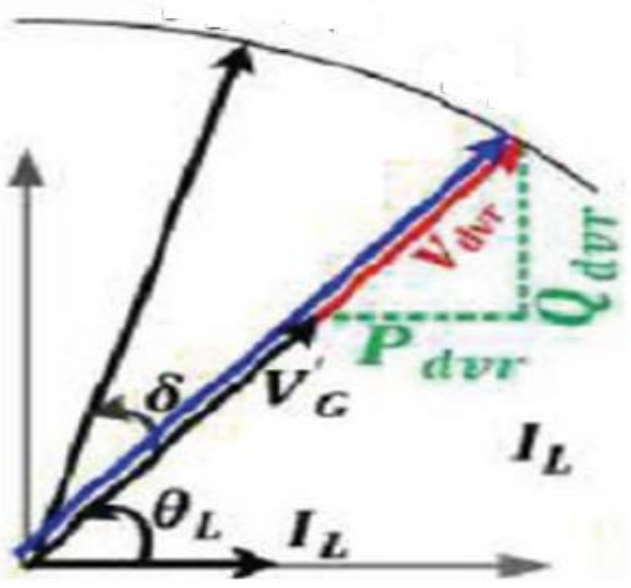

Fig.12 DC bus voltage with symmetrical voltage sag

A basic circuit of Dynamic Voltage Restorer is shown in Figure 11. When the net work voltage reduces due to reason such as sudden increase in load etc, the DVR injects a voltage in such away that the desired network voltage can be maintained. The vector diagram shows the required injected voltage for correcting a given amount of sag. The grid phasea angle can be found out using Phase locked loop.Fig.12 shows the vector diagram with series voltage injection. The magnitude of the injected voltage is given by Eqn.3, in which ' $V s$ 'represent the grid voltage,' $V d f i g$ ' represent the DFIG terminal voltage.' $V d v r$ ' is the injected voltage by the DVR.The series compensation is achieved by injecting the required amount of voltage to the grid using the three single phase transformer. The monitoring of dc link voltage is very essential due the reason that active power transfer is happening through dc link.. A phase locked loop is employed to obtain the phase angle for injecting the voltage at correct phase angle.. The control generates the ' $\mathrm{dq}$ ' reference which is transformed to the three phase stationary reference frame value in order to generate correct control signal for the PWM modulation. To verify the effectiveness of the proposed method of control of DVR simulation has been done using MATLAB on a $2 \mathrm{MW}$ DFIG system, by choosing a wind speed of $11 \mathrm{~m} / \mathrm{s}$. For simulation purpose maximum sag of $90 \%$ is given from 3 seconds to a time period of 1.2 seconds.Figure.13 shows the variation of grid voltage, after the sag, the voltage increases in a ramp manner.Figure14 shows the variation of DVR injected voltage. It is evident form the figure that as the grid voltage increases after the sag the injected voltage from the DVR decreases. Figure 15 shows the DFIG terminal voltage after compensation using Dynamic voltage restorer. Figures 16 and 17 shows the variation in rotor current and dc bus voltage. .On comparison with the value of rotor current without compensation it is clear that the value of rotor current reduces due to compensation.

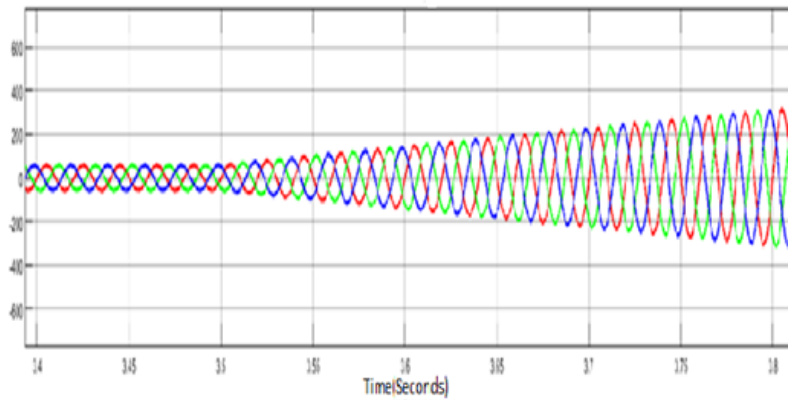

Fig.13 Grid Voltage.

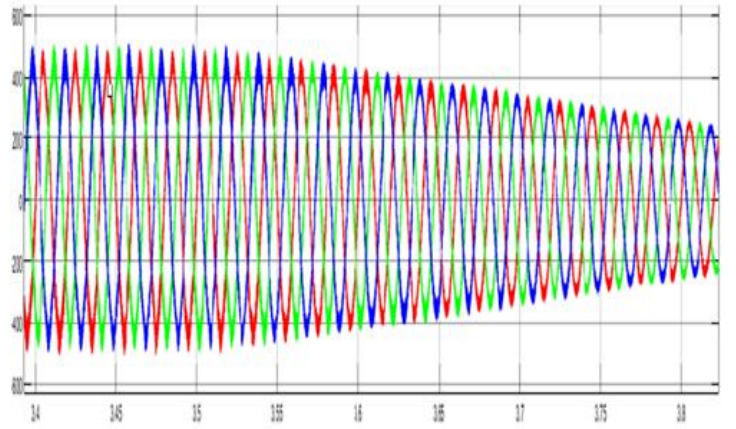

Fig.14 DVR Injected voltage with symmetrical sag

Published By:

Blue Eyes Intelligence Engineering

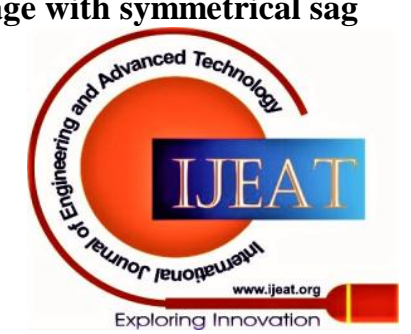




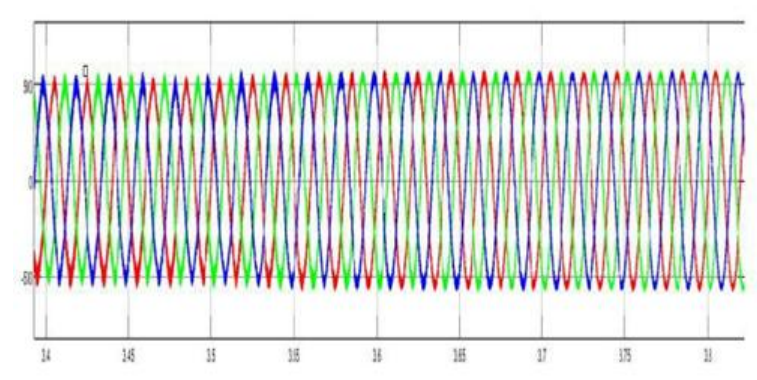

Fig.15 DFIG Terminal voltage with symmetrical sag

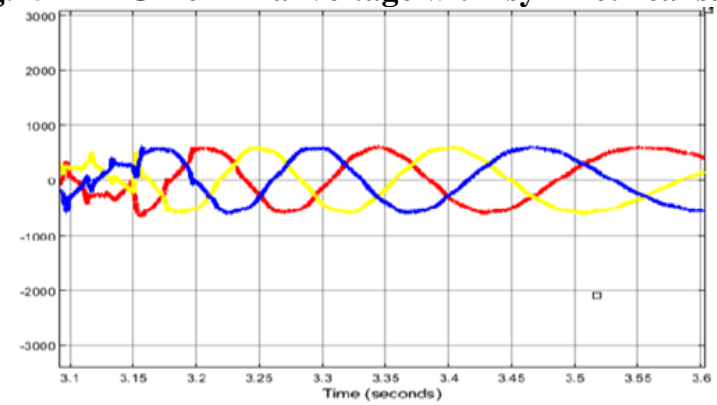

Fig.16 DFIG Rotor current with symmetrical sag

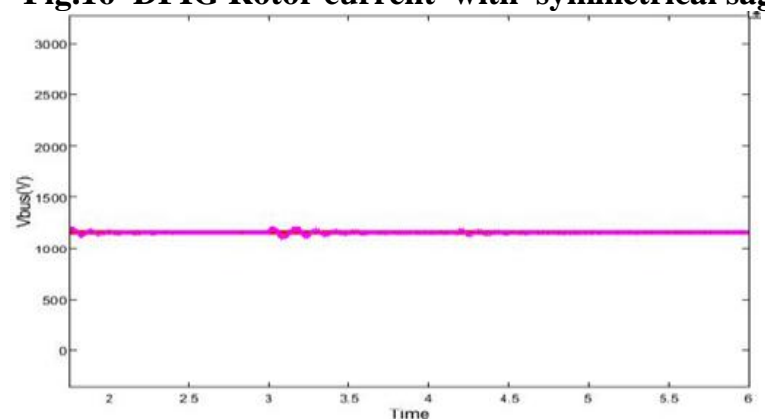

Fig.17 DFIG DC bus voltage with symmetrical sag

$$
V_{d v r}=\sqrt{V_{s}^{2}+V_{\text {dfig }}^{2}-2 V_{s} V_{\text {dfig }} \cos \delta}
$$

\section{CONCLUSION}

This paper gives behavior of grid connected Doubly Fed induction Generator under symmetrical network unbalance voltage .Also here the Authors analyses the application of Dynamic Voltage Restorer to improve the fault ride- through capability of DFIG based wind Turbine system. To show the complete behavior of DFIG, during grid voltage disturbances, simulation result of 2 MW DFIG system are presented. From the various result obtained through MATLAB simulation it is under stood that the proposed control method is very effective.

\section{APPENDIX--I}

$2 \mathrm{~kW}, 690 \mathrm{~V}, 50 \mathrm{~Hz}$ generator parameters

Stator resistance, $\mathrm{Rs}=0.19 \Omega$

Rotor resistance , $\mathrm{R}_{\mathrm{r}}=0.39 \Omega$

Number of Poles ,P $=4$

Magnetizing inductance, $\mathrm{Lm}=4 \mathrm{mH}$

Stator leakage inductance, $\mathrm{Lls}=0.21 \mathrm{mH}$.

Rotor leakage inductance, $\mathrm{Lrr}=0.6 \mathrm{mH}$

Stator inductances $=4.21 \mathrm{mH}$

Rotor inductance $=4.6 \mathrm{mH}$

Moment of inertia $\mathrm{J}=0.0226 \mathrm{Nm} /(\mathrm{rad} \mathrm{s})$

Damping constant $=0.2 \mathrm{Nm} /\left(\mathrm{rad} \mathrm{s}^{2}\right)$

\section{REFERENCES}

1. Singh, Bhim, Shiv Kumar Aggarwal, and Tara Chandra Kandpal. "Performanceof Wind Energy Conversion System Using a Doubly Fed Induction Generator for Maximum Power Point Tracking", IEEE Industry Applications SocietyAnnual Meeting, vol. 139, no. 5, pp. 429-442, July 2010.

2. Bimal K Bose,"Modern Power electronics and ac drives"PHI Learning Private Limited.

3. Ned Mohan, Ted K. A. Brekken "Control of a Doubly Fed Induction Wind Generator Under Unbalanced Grid Voltage Conditions" IEEE Transaction Energy conversion, vol.no22. 1, March 2007 page 129-135

4. Heng Nian, Member, IEEE, and Yipeng Song," Direct Power Control of Doubly Fed Induction Generator Under Distorted Grid Voltage" IEEE Transactions on Power Electronics, vol. 29, no. 2, February 2014

\section{AUTHORS PROFILE}

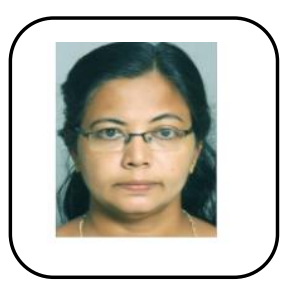

T.Samina. was born in Kollam, Kerala,. She received her B.Tech degree in Elecrtical \& Electronics Engineering ,from Kerala University, and her M.Tech degree in Power Systems from National Institute of Technology, Tiruchirappalli. Currently she is pursuing her Ph.D. degree in Power systems from Kerala University. Her employment experience includes Industrial experience in Power system Field and Teaching experience. Currently she is working as associate Professor, in College of Engineering, Thiruvanathapuram .Her area of interest includes Power systems, Wind power Technology, Power Electronics etc..

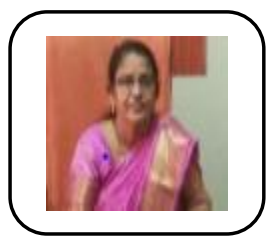

A.Bisharthu Beevi. Was born in Kerala. She received her B.Tech degree in Electrical \& Electronics engineering in 1986, M.Tech degree in Power Systems in 2000 and Ph.D degree in Power systems in 2011,from Kerala University .She has started her career as Lecturer in Electrical Engineering in 1992 at Govt .Engineering College, Kannur and served in various engineering colleges across Kerala. She has a total of 29 years of Teaching Research and Administrative Experience. She has published more than 65 papers in reputed journals and conferences. Her research field includes power Systems, Power Electronics etc..

S.RamaIyer.,was born in Kerala. He Received his M.Tech and Ph.D Degree in Power Systems, from Indian institute of Technology, Delhi. He served as professor in Electrical Department, and as Dean in College of Engineering, Thiruvananthapuram His research area includes Power Systems, Power Electronics, etc. He is the owner of a large number of publications in various reputed journals in the field of Power systems. Currently he retired from Government service and guiding a number of Research Scholars.

\section{Published By:}

Blue Eyes Intelligence Engineering and Sciences Publication

(C) Convriaht: All riahts reserved.

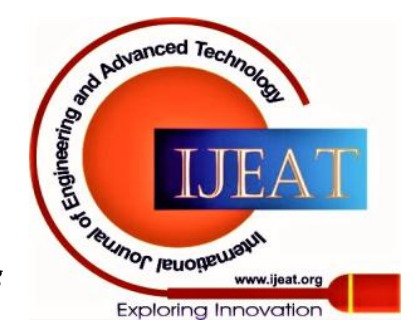

